\title{
Thermoluminescence Energy Response of Copper and Magnesium Oxide Doped Lithium Potassium Borate Using a Monte Carlo N-Particle Code Simulation
}

\author{
Khaled M. Abushab ${ }^{1}$, Yasser S. Alajeramii ${ }^{12 *}$, Sami Alagha1 ${ }^{1}$, Suhairul Hashim² \\ ${ }^{1}$ Department of Medical Radiography, Al-Azhar University, Gaza Strip, Palestine \\ ${ }^{2}$ Department of Physics, Universiti Teknologi Malaysia, Skudai, Malaysia \\ Email: *yasser_ajr@hotmail.com
}

How to cite this paper: Abushab, K.M., Alajerami, Y.S., Alagha, S. and Hashim, S. (2017) Thermoluminescence Energy Response of Copper and Magnesium Oxide Doped Lithium Potassium Borate Using a Monte Carlo N-Particle Code Simulation. International Journal of Medical Physics, Clinical Engineering and Radiation Onco$\log y, 6,304-312$.

https://doi.org/10.4236/ijmpcero.2017.63027

Received: May 5, 2017

Accepted: August 13, 2017

Published: August 17, 2017

Copyright (๑) 2017 by authors and Scientific Research Publishing Inc. This work is licensed under the Creative Commons Attribution International License (CC BY 4.0).

http://creativecommons.org/licenses/by/4.0/ c) (†) Open Access

\begin{abstract}
The energy absorption coefficient of $\mathrm{Cu}$-doped lithium potassium borate (LKB) dosimeter and TLD 100 was reported theoretically and checked by simulation of Monte Carlo n-particle code version 5 (MCNP5). The response of LKB:Cu for various photon energies (20 keV to $10 \mathrm{MeV})$ were determined by calculation, experiment and simulation. The obtained results were discussed and compared with TLD 100. For more precise results, the geometry specification, the source information, the material information and tallies were identified and fully described. The results obtained by simulation were determined based on the tally F6, which exhibited the response as energy-dependant on heating function instead of flux. The current results showed that the prepared dosimeter has a greater response than TLD 100 in the lower energy range and a flat response in the higher energy ranges $(\geq 100 \mathrm{keV})$.
\end{abstract}

\section{Keywords}

Thermoluminescence, MCNP, Lithium Potassium Borate, Energy Response

\section{Introduction}

There is over a century, in November 1895, Wilhelm Conrad Roentgen discovered the X-ray. A few months later, in March 1896, Henri Becquerel described the radioactivity [1]. The use of ionizing radiation has become increasingly frequent and diverse in recent decades. Today the radiation is used in many sectors of medical, industrial, military and research. Ionizing Radiation is a type of radi- 
ation characterized by its short wave length and high frequency, and its ability to produce free radicals (ions) when it interacts with matter. It can remove the tightly bounded electrons from the shell of the exposed atom and cause the atom to become charged or ionized. This radiation consists of particles (e.g. alpha, beta and neutron) or electromagnetic waves ( $\mathrm{x}$-ray and gamma ray) that are energetic enough to cause ionization and severe biological damage when it is absorbed by human tissues. In dead, the high doses of ionizing radiation can cause mutation, cancer, radiation sickness, and death [2]. Whatever the type of application, it is often necessary or essential to measure the energy deposited per unit mass during the interaction of radiation with the target. The physical quantity characterizing this concept is called the absorbed dose and is expressed in Gray (Gy). The absorbed dose determination is one of the main objectives of all radiation-related studies. The thermoluminescence dosimeter (TLD) is one of the most appropriate methods for absorbed dose estimation. This phenomenon makes the gate wide open for a lot of researches in order to prepare a perfect dosimeter. Generally, the ideal thermoluminescent material is expected to show a series of properties i.e. the effective atomic number close to human tissues, dose response linearity, signals stability, reproducibility and simple annealing process. Recently, many phosphors are commercially available and have been used in different ionizing radiation disciplines. Unfortunately, none of the available dosimeters can cover all the previous TL properties. The borate glasses possess attractive properties make it one of the competitive material, particularly its promising effective atomic number and easiness annealing process [3] [4] [5] [6].

Nowadays, majority of physical experiments are jointed with mathematic or numerical calculations by using radiation transport code [7]. In radiation protection and dosimetry, the simulation becomes one of the most significant tools that is used to assure the results obtained by experiments; particularly, in the process of absorbed dose determination after the radiation accident. MCNP5 is one of the most powerful simulations that is widely used in medical physics. This code has the advantage of being documented and subjected to regular updates. Initially, MCNP is designed for calculation involving neutrons only. Then, it was subsequently generalized to the transport of photons and electrons in a wide energy range; finally, the positron was included during the coding of MCNP5. Currently, MCNPTM code version 5 (V5) provides continuous-energy, generalized-geometry, time-dependent code and can be used for single, couple or more of neutron/photon/electron transport. One main difference of MCNP from other Monte Carlo codes is that MCNP can be run in several different modes. By default, mode $\mathrm{N}$ is used; neutron transport only [8].

The current work aims to compare between the simulated, theoretical and experimental energy responses of newly prepared dosimeter. The proposed dosimeter is boric glass modified with lithium and potassium carbonate (LKB) and co-doped with copper and magnesium oxide. The dosimetric properties of the new dosimeter were determined in previous work [9]. The obtained results are also compared 
against the standard commercial dosimeter LiF:Mg,Ti (TLD-100).

\section{Methods}

The current work focuses to estimate the energy response of new prepared dosimeter experimental, theoretical and simulation. Experimentally, the prepared phosphor is prepared based on the quenching technique using the raw material illustrates on the following expression:

$$
10 \mathrm{~K}_{2} \mathrm{CO}_{3}: 20 \mathrm{Li}_{2} \mathrm{CO}_{3}:(69.80-x) \mathrm{HB}_{3} \mathrm{O}_{3}: 0.1 \mathrm{CuO}+0.1 \mathrm{MgO}
$$

These concentrations were determined based on a previous study done by our group to specify the best TL response associated with the material proportions. The resultant glasses are prepared in a rectangular form $\left(2.5 \times 2.5 \times 1 \mathrm{~mm}^{3}\right)$ and exposed to different energy sources started from $20 \mathrm{keV}$ up to $10 \mathrm{MeV}$. The thermoluminescent glow curve measurements of the current samples were carried out by using Harshaw 4500 Manual Model TLD Reader at Physics Department of Universiti Teknologi Malaysia. All TL responses were determined at fixed heating treatment in the range of 50 up to $400^{\circ} \mathrm{C}$.

Theoretically, McKeever and Chen [10] derived a simple formula to determine the dosimetric energy response. This formula is potentially depending on the mass energy absorption coefficient (MEAC) of the exposed phosphor and reference material:

$$
S(E)=\frac{\left(\mu_{e n} / \rho\right)_{m}}{\left(\mu_{e n} / \rho\right)_{\text {ref }}}
$$

where $\left(\mu_{e n} / \rho\right)_{m}$ and $\left(\mu_{e n} / \rho\right)_{\text {ref }}$ are the mass energy coefficient of the TLD material and reference material, respectively. In the current study, the reference material is air. The mass energy coefficient of the current mixture was determined according Equation (2). Two independent factors are required to apply this equation the mass energy of the elemental composition and the weight fraction of each element. In 1995, Hubbell and Seltzer tabulated the mass energy coefficient values for the majority of chemicals [11]. Respect to the weight fraction of the proposed dosimeter, the elemental composition of the current dosimeter was determined by the field emission scanning electron microscopy (FESEM).

$$
\left(\frac{\mu_{e n}}{\rho}\right)_{m}=\sum_{i}\left(\frac{\mu_{e n}}{\rho}\right)_{i} W_{i}
$$

For practical use, the relative energy response (RER) was calculated with respect to the energy response of standard radioactive source (i.e. ${ }^{60} \mathrm{Co}$ ). It is well known that cobalt-60 emits two divorced photon-energy response one with 1.17 $\mathrm{MeV}$ and the other with $1.33-\mathrm{MeV}$. In this research, the photon energy response of cobalt is calculated at the $1.25 \mathrm{MeV}$ (the average of the two emitted energies).

$$
R E R=\frac{S_{E}(E)}{\left(S_{E} 1.25 \mathrm{MeV} 60 \mathrm{Co}\right)}
$$

Finally, the simulation study was carried out by Monte Carlo $\mathrm{N}$ particle code version 5 (MCNP5). For comparison study, two different codes were designed 
Table 1. The required details of LiF:Ti, Mg and LKB:Cu,Mg.

\begin{tabular}{cccc}
\hline & Dimension & Density & Material State \\
\hline LiF:Ti,Mg & $3.3 \times 3.3 \times 0.9 \mathrm{~cm}^{3}$ & $2.64 \mathrm{~g} \cdot \mathrm{cm}^{-3}$ & Crystal chip \\
LKB:Cu,Mg & $2.5 \times 2.5 \times 1 \mathrm{~mm}^{3}$ & $2.29 \mathrm{~g} \cdot \mathrm{cm}^{-3}$ & Glass chip \\
\hline
\end{tabular}

one for $\mathrm{LKB}: \mathrm{Cu}, \mathrm{Mg}$ and the other for $\mathrm{LiF}: \mathrm{Ti}, \mathrm{Mg}$. The previous codes have the same simulation criteria of tally and source specifications and different target design and composition. Table 1 shows the required details of the TLD-100 and the newly prepared dosimeter. In each simulation, 50 phosphors were placed in a tray which designed to be in a solid phantom at the depth of $1.5 \mathrm{~cm}$ from the surface and $100 \mathrm{~cm}$ from the source. This phantom was proposed to be filled with $8 \%$ hydrogen, $32 \%$ oxygen and $60 \%$ carbon and a total density of 1.19 $\mathrm{g} \cdot \mathrm{cm}^{-3}$. The source (point source collimated into a cone direction) and the type of radiation particle (photon) are identified by the source specification card (SDEF) command. Each energy source was run with 100 million histories (nps). The design (source and target) was performed inside a sphere with $120 \mathrm{~cm}$ diameter. The space between the phantom and the sphere was considered as dry air [12].

The estimation energy response by simulation was carried out through three substantial steps. Firstly, the energy absorbed normalized to the mass of dosimeter $\left(\mathrm{MeV} \cdot \mathrm{g}^{-1}\right)$ is retrieved after each simulation run, $\mathrm{E}_{\mathrm{abs}}$. Secondly, this value was used to determine the mass energy absorption coefficient $\left(\mathrm{cm}^{2} \cdot \mathrm{g}^{-1}\right)$ by the following equation:

$$
f(E)=\frac{E_{a b s} \mathrm{Mev} \cdot g^{-1} \times 1 \mathrm{~cm}^{2}}{E \mathrm{MeV}}
$$

where $f(E)$ is the mass energy absorption coefficient, which corresponding to the average fraction of deposited energy, $E_{a b s}$ energy deposited normalized to the mass of each dosimeter, is the energy of the incident photon by MeV.

Finally, the photon energy response is obtained by normalized to the average fraction of deposited energy to the mass energy absorption coefficient of reference material (air) as shown in Equation (5).

$$
S(E)=\frac{f(E)}{\left(\mu_{e n} / \rho\right)_{\text {air }}}
$$

The relative energy response was determined with the same equation used in theoretical equation (Equation (3)).

\section{Results and Discussion}

The mass absorption coefficient of ninety energies $(20,30,40,50,60,80,100$, $150,200,300,500,800,900 \mathrm{keV}$ and 1.25, 2, 4, 6, 8 and $10 \mathrm{MeV}$ ) were calculated (Equation (2)) and run by MCNP5 (Equation (4)) for TLD-100 and LKB:Cu,Mg. The weight fractions of the elemental composition of TLD-100 and LKB:Cu, Mg are listed in Table 2. Figure 1 shows the mass absorption coefficient values 
Table 2. Weight fractions of the elemental composition of LiF:Ti,Mg and LKB:Cu,Mg.

\begin{tabular}{ccc}
\hline Element & LiF:Ti,Mg & LKB:Cu,Mg \\
\hline Lithium & 0.2672 & 0.146 \\
Boron & - & 0.784 \\
Fluorine & 0.7328 & - \\
Magnesium & 0.0002 & 0.002 \\
Potassium & - & 0.065 \\
Titanium & 0.00001 & - \\
Copper & - & 0.003 \\
\hline
\end{tabular}

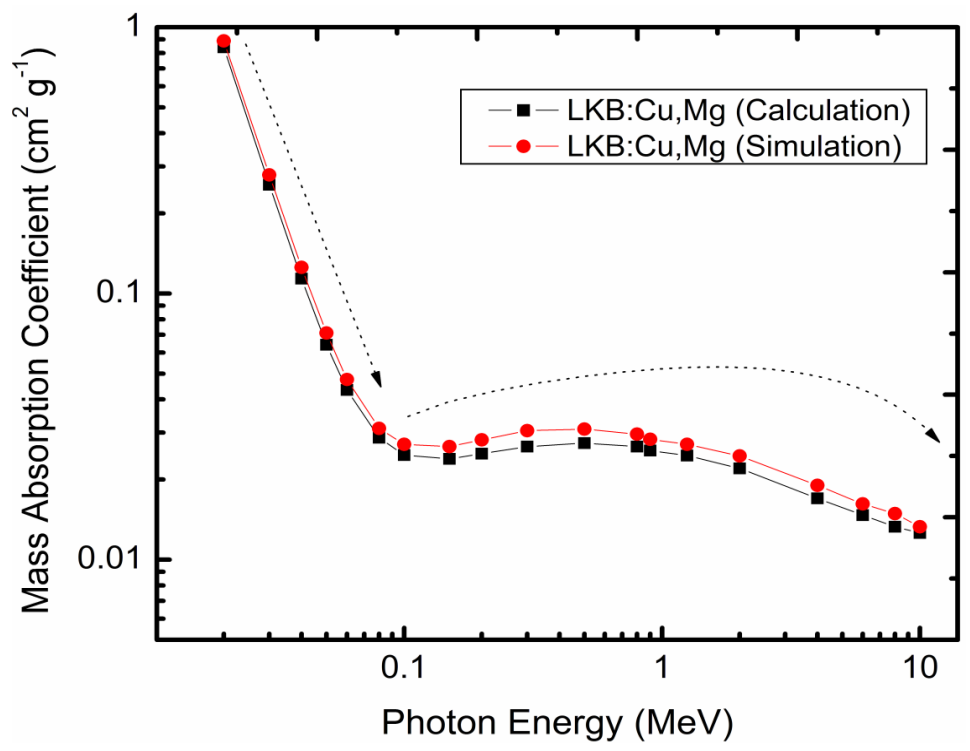

Figure 1. Calculation and simulation of mass absorption coefficient of LKB:Cu, Mg.

obtained by calculation and simulation. Obviously, the simulation values are very close at low energies and slightly higher than MEAC at high energies $(>100$ $\mathrm{keV}$ ). This variation can attribute to the simplicity of the MCNP assumption compared to the actual calculation which considered much more complex [13] [14]. The mass absorption coefficient of TLD-100 in TL material obtained from calculation and MCNP simulation was reported in Figure 2. The achieved results show a great similarity between $\mathrm{LKB}: \mathrm{Cu}, \mathrm{Mg}$ and TLD-100.

From Figure 1, the prepared dosimeter (LKB: $\mathrm{Cu}, \mathrm{Mg}$ ) is higher than MEAC except for energy of $20 \mathrm{keV}$. Regarding TLD 100, difference values between calculation and simulation could be due to simplifying assumption in generating simulation. It is shown that the mass energy absorption coefficient $\left(\mathrm{cm}^{2} \cdot \mathrm{g}^{-1}\right)$ show same pattern of response from each material. Both figures show that mass energy absorption coefficient as a function of photon energies for $\mathrm{LKB}: \mathrm{Cu}, \mathrm{Mg}$, and TLD 100 materials decrease rapidly from $20 \mathrm{keV}$ to $100 \mathrm{keV}$ and then remain slowly decrease until $10 \mathrm{MeV}$. Theoretical calculations of photon energy responses of both dosimeters for mass energy absorption coefficient are good agreement with Monte Carlo Simulation. 


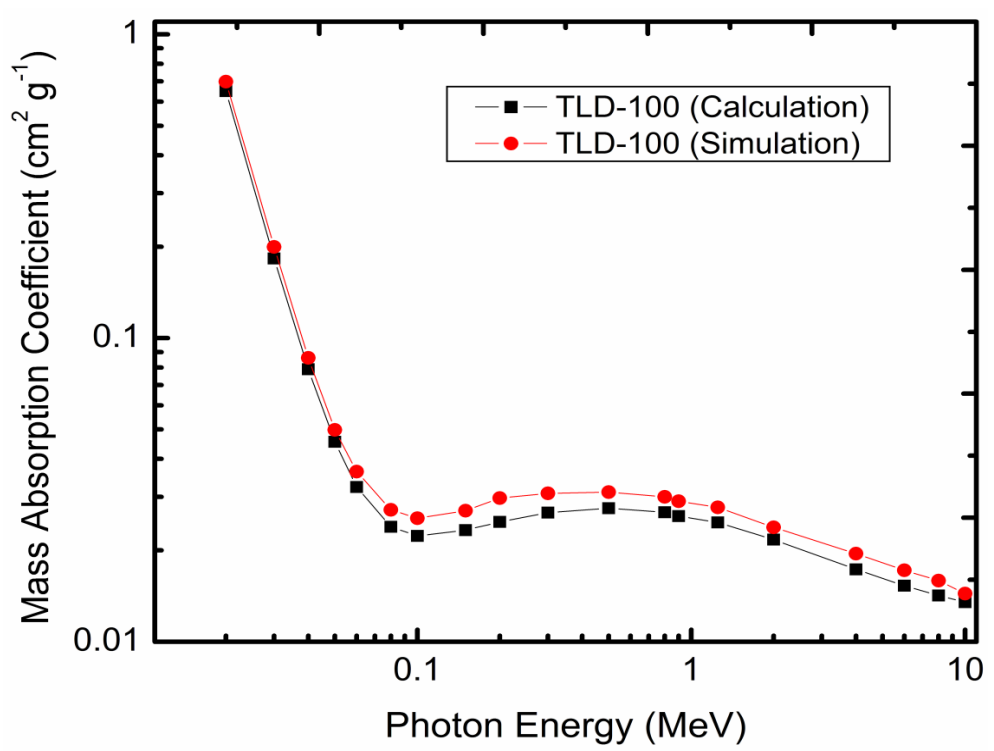

Figure 2. Calculation and simulation of mass absorption coefficient of TLD 100.

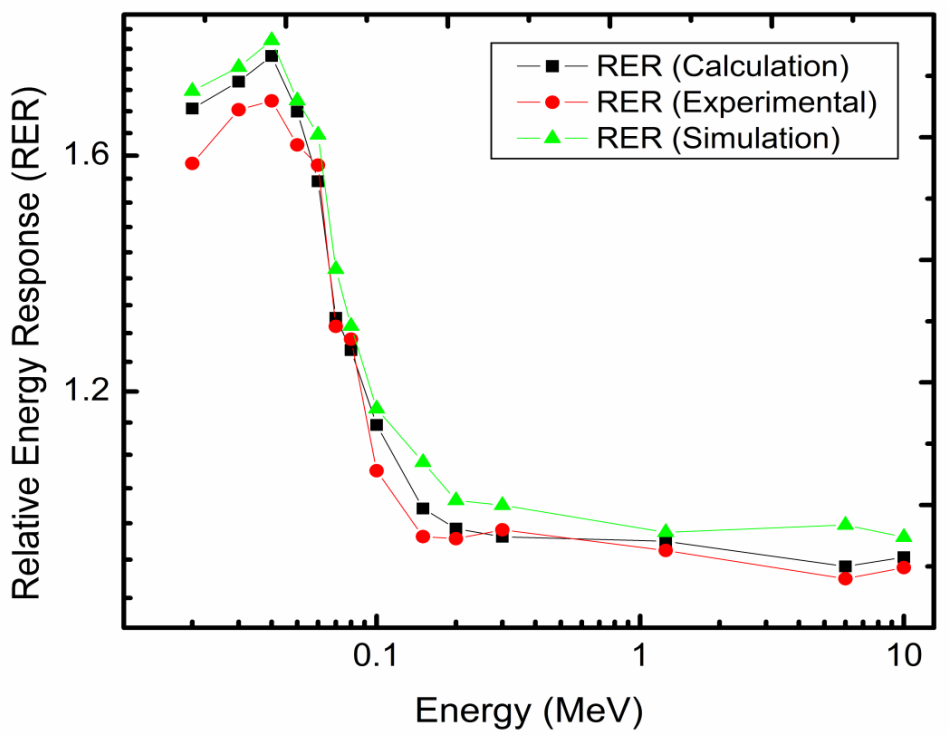

Figure 3. Relative energy responses of $\mathrm{LKB}: \mathrm{Cu}, \mathrm{Mg}$ by calculation, experimentally and simulation.

Figure 3 shows the relative energy responses obtained by theoretical, experimental, and MCNP simulation for LKB:Cu, Mg at 20, 30, 40, 50, 60, 80, 100, 150, $200,300 \mathrm{keV}$ and $1.25,6$ and $10 \mathrm{MeV}$. It is clearly shown the rapidly increasing of theoretical relative energy response in the energy range from $20 \mathrm{keV}$ to 40 $\mathrm{keV}$. Beyond this energy level, the RER is reduced dramatically up to $100 \mathrm{keV}$. Finally, an equal response was achieved (RER 1) from the $100 \mathrm{keV}$ to $10 \mathrm{MeV}$. Experimentally, the LKB:Cu,Mg exhibits the highest RER value at $40 \mathrm{keV}$ and becomes to reduce in parallel with the raising of photon energies. The RER becomes constant and equal 1 on the range of $100 \mathrm{keV}$ up to $10 \mathrm{MeV}$. Respect to the simulation energy response, a close behaviour is observed. It can show the rapidly reduction of RER from 40 to $150 \mathrm{keV}$, and then remain constant until 10 
Table 3. Experimental and simulated Relative Energy Response of TLD 100.

\begin{tabular}{ccccccc}
\hline \multirow{2}{*}{ Energy, $(\mathrm{MeV})$} & \multicolumn{2}{c}{ RER } & \multirow{2}{*}{ Rergy, $(\mathrm{MeV})$} & \multicolumn{2}{c}{ RER } \\
\cline { 2 - 3 } \cline { 6 - 7 } & Exp. & Sim. & & & Exp. & Sim. \\
\hline $\mathbf{0 . 0 2}$ & 1.277 & 1.312 & $\mathbf{0 . 1 5}$ & 1.011 & 1.015 \\
$\mathbf{0 . 0 3}$ & 1.281 & 1.295 & $\mathbf{0 . 2 0}$ & 1.015 & 1.015 \\
$\mathbf{0 . 0 4}$ & 1.248 & 1.232 & $\mathbf{0 . 3 0}$ & 1.000 & 1.000 \\
$\mathbf{0 . 0 5}$ & 1.201 & 1.222 & 1.25 & 1.000 & 1.005 \\
$\mathbf{0 . 0 6}$ & 1.152 & 1.165 & $\mathbf{6 . 0 0}$ & 1.005 & 1.010 \\
$\mathbf{0 . 0 8}$ & 1.065 & 1.081 & 10.00 & 1.002 & 1.010 \\
$\mathbf{0 . 1 0}$ & 1.038 & 1.045 & & & \\
\hline
\end{tabular}

$\mathrm{MeV}$. Almost all the RER values obtained by simulation were slightly higher than those obtained by calculation and experimental responses. The previous estimation methods of RER show that the $\mathrm{LKB}: \mathrm{Cu}, \mathrm{Mg}$ has a stable response in the range of $100 \mathrm{keV}$ to $10 \mathrm{MeV}$.

Table 3 listed the experimental and simulated energy response of TLD-100. A close pattern of energy response is obtained from each dosimeter especially from $100 \mathrm{keV}$ to $10 \mathrm{MeV}$. In both cases, the RER is reduced with spontaneous increasing of photon energies and becomes flat within the energy levels of 0.1 and $10 \mathrm{MeV}$. The current result indicates that the maximum responses at $40 \mathrm{keV}$ for LKB: $\mathrm{Cu}, \mathrm{Mg}$ and TLD-100 are found to be 1.7 and 1.2, respectively. Hence, the prepared dosimeter has greater response than the TLD-100 by a factor of 1.4 at low energies (20 to $40 \mathrm{KeV}$ ).

The current dosimeter provides an extensive application in "radiation monitoring and absorbed dose calculation". In other words, it is used to determine the amount of radiation that a person is exposed to either from the working environment or due to medical treatment (in cancer treatments). In personnel dosimetry, the proposed dosimeter ( $\mathrm{LKB}: \mathrm{Cu}, \mathrm{Mg}$ ) provided the employee with the simple apparatus that containing the thermoluminophore, namely the dosimeter, and the amount of radiation that he/she is exposed to is measured periodically. These measurements are of great importance regarding the occupational health and safety aspect. The authority is responsible for the health of its employees and the situation is quite serious in the working places with such a severe health risk like radiation. These work places include nuclear stations and radiotherapy departments of hospitals. Besides, it is of significance to monitor the amount of radiation a patient is given. For this purpose in-vivo (in-body) dosimeters are developed to monitor the success of the treatment applied.

In the current study, experiments, simulations, and models belong to the same category of scientific tools. Where models and simulations stand on the theory's side at one end of the spectrum, and experiments stand on the world's side at the other end. The experiment, simulation, or "simulating experiment" must mirror the target in a number of relevant aspects. Fabrication errors and faults of dosimeters come out due to devices, human force, and/or bad material. So, if your 
numerical work is exact and based on theoretical concepts is in one direction (finite element method and/or software results).

\section{Conclusion}

The mass energy absorption coefficient of LKB:Cu,Mg and TLD 100 have successfully calculated and confirmed by performing MCNP5 simulation in the range of $20 \mathrm{keV}-10 \mathrm{MeV}$. Consequently, the photon energy responses of TLD100 and new prepared borate dosimeter have been determined experimentally, theoretically and by using a MCNP5 simulation. The obtained results indicated that the proposed dosimeter is a good TL material and has a promising energy response when exposed to photon irradiation in the energy range from $100 \mathrm{keV}$ to $10 \mathrm{MeV}$. Simulation results for the energy response for $\mathrm{LKB}: \mathrm{Cu}, \mathrm{Mg}$ are in good agreement with the theoretically and experimental values. It can be shown that there is a hump in the response to energies between 40 and $100 \mathrm{keV}$, which indicating how much the measured dose deviates from the dose response of 1.00. The results of the simulation are very close to the experimental and theoretical calculations, particularly at low energies. Distinction in the experimental and theoretical values are obtained at high energies $(>100 \mathrm{keV})$. This variation can attribute to the simplicity of the MCNP assumption compared to the expected experimental faults. In the mentioned energy region, the photoelectric effect is the dominant interaction. The photoelectric component of the mass energy absorption coefficient of a certain element varies approximately $\mathrm{Z}^{3}-\mathrm{Z}^{4}$. Furthermore, it is noted that the RER for LKB:Cu, Mg is $\sim 1.80$ times higher at $40 \mathrm{keV}$, respectively.

\section{Acknowledgements}

The authors are thankful to Qatar Charity Institute for the financial support through IBHATH Grant, Project No. R.J130000.7826.4F168. This work was partially supported by Al-Azhar University, Gaza.

\section{References}

[1] Eric, J.H. and Amato, J.G. (2006) Radiobiology for the Radiologist. 6th Edition, Lippinco Hwillians and Wilkins, Philadelphia.

[2] Little, M.P. (2003) Risks Associated with Ionizing Radiation. British Medical Bulletin, 68, 259-275. https://doi.org/10.1093/bmb/ldg031

[3] Santiago, M., Lester, M., Caselli, E., Lavat, A., Ges, A., Spanof, F. and Kessler, C. (1998) Thermoluminescence of Sodium Borate Compounds Containing Copper. Journal of Materials Science Letters, 17, 1293-1296. https://doi.org/10.1023/A:1006576112776

[4] Can, N., Karali, T., Townsend, P.D. and Yildiz, F. (2006) TL and EPR Studies of Cu, Ag and P Doped Li2B4O7 Phosphor. Journal of Physics D: Applied Physics, 39, 2038. https://doi.org/10.1088/0022-3727/39/10/009

[5] Sasaki, T., Mori, Y., Yoshimura, M., Yap, Y.K. and Kamimura, T. (2000) Recent Development of Nonlinear Optical Borate Crystals: Key Materials for Generation of Visible and UV Light. Materials Science and Engineering. R: Reports, 30, 1-54. https://doi.org/10.1016/S0927-796X(00)00025-5 
[6] Ghotbi, M. and Ebrahim-Zadeh, M. (2004) Optical Second Harmonic Generation Properties of $\mathrm{BiB}_{3} \mathrm{O}_{6}$. Optics Express, 12, 6002-6019. https://doi.org/10.1364/OPEX.12.006002

[7] Takahashi, F. and Endo. A. (2007) Numerical System Utilizing a Monte Carlo Calculation Method for Precise Dose Assessment in Radiation Accidents. Radiation Protection Dosimetry, 126, 595-599. https://doi.org/10.1093/rpd/ncm121

[8] X-5 Monte Carlo Team (2003) MCNP_A General N-Particle Transport Code, Version 5. Volume I: Overview and Theory. Los Alamos National Laboratory, Los Alamos.

[9] Alajerami, S.M.Y., Hashim, S., Ramli, A.T., Saleh, M.A. and Kadni, T. (2013) Thermoluminescence Properties of $\mathrm{Li}_{2} \mathrm{CO}_{3}-\mathrm{K}_{2} \mathrm{CO}_{3}-\mathrm{H}_{3} \mathrm{BO}_{3}$ Glass System Co-Doped with $\mathrm{CuO}$ and $\mathrm{MgO}$. Radiation Protection Dosimetry, 155, 1-10.

https://doi.org/10.1093/rpd/ncs310

[10] McKeever, S.W. and Chen, R. (1997) Theory of Thermoluminescence and Related Phenomena. World Scientific, Singapore.

[11] Hubbell, J.H. and Seltzer, S.M. (1995) Tables of X-Ray Mass Attenuation Coefficients and Mass Energy-Absorption Coefficients. National Institute of Standards and Technology, Gaithersburg.

[12] X-5 Monte Carlo Team (2005) MCNP-A General Monte Carlo N-Particle Transport Code, Version 5 (1-2). Los Alamos National Laboratory, Los Alamos.

[13] Hossain, H., Wagiran, H. and Asni, A.T. (2012) Mass Energy Absorption Coefficients for 0.2-20 MeV Photon in Ge-Doped Optical Fiber and TLD-100 by Monte Carlo N-Particle Code Version 5 (MCNP5) Optoelectronics and Advanced Materials. Rapid Communications, 6, 162-164.

[14] Wagiran, H., Hossain, I.H. and Asni, A.T. (2011) Thermoluminescence Energy Response of a Germanium-Doped Optical Fiber Obtained Using a Monte Carlo N-Particle Code Simulation. Journal of the Korean Physical Society, 59, 337-340. https://doi.org/10.3938/jkps.59.337

\section{Scientific Research Publishing}

\section{Submit or recommend next manuscript to SCIRP and we will provide best service for you:}

Accepting pre-submission inquiries through Email, Facebook, LinkedIn, Twitter, etc. A wide selection of journals (inclusive of 9 subjects, more than 200 journals)

Providing 24-hour high-quality service

User-friendly online submission system

Fair and swift peer-review system

Efficient typesetting and proofreading procedure

Display of the result of downloads and visits, as well as the number of cited articles

Maximum dissemination of your research work

Submit your manuscript at: http://papersubmission.scirp.org/

Or contact ijmpcero@scirp.org 